\section{Diarios de}

motocicleta: um

diário de imagens cifradas

Christiane Silveira Batista

Paulo Custódio de Oliveira

Recebido em: 18 de fevereiro de 2019

Aceito em: 4 de maio de 2019
Christiane Silveira Batista é mestra em Letras pela Universidade Federal da Grande Dourados (UFGD), especialista em Língua Espanhola pela Faculdade Internacional Signorelli e graduada em Letras pela Universidade Federal de Mato Grosso do Sul (UFMS). Atualmente, exerce o cargo de Técnica em Assuntos Educacionais na UFGD $i$ é bolsista formadora em Língua Espanhola no Centro de Formação UFGD Eixo Línguas Estrangeiras; compõe - Grupo de Estudo InterArtes/ UFGD e a comissão organizadora do Seminário de Literatura e Artes Contemporânea (SELAC).

Contato:christianebatista@ufgd. edu.br

Brasil

Paulo Custódio de Oliveira é coordenador do Grupo de Estudo InterArtes e do Laboratório InterArtes de Mídia e Imagem (Liami)da Universidade Federal da Grande Dourados (UFGD), onde se pesquisa a relação da literatura com outras artes (em especial com o cinema). Pósdoutor pela Universidade Federal Fluminense (UFF). Doutor pela Universidade Estadual Paulista "Júlio de Mesquita Filho"(Unesp). Professor do Programa de PósGraduação em Letras da Faculdade de Comunicação, Artes e Letras (Facale) da UFGD.

Contato:pensepaulo@gmail.com Brasil 


\section{PALAVRAS-CHAVE:}

Literatura comparada; Diarios

de Motocicleta; Che

Guevara; Paratexto.
KEYWORDS: Comparative

literature; Motorcycle diaries; Che Guevara; Paratext.
Resumo: A obra em língua espanhola Diarios de motocicleta (2004), de Ernesto Rafael Guevara de la Serna, o Che Guevara, é uma das edições de seu diário de viagem escrito entre 1951 e 1952. Esse material foi revisado e narrativizado por ele tempos depois e esteve em posse de seus familiares por aproximadamente 40 anos até a autorização de sua primeira publicação, intitulada Notas de Viaje (1993). Nesta investigação, é apresentada a cronologia das edições até se chegar à última edição ampliada para, por meio da análise comparativa das edições, salientar algumas das alterações editoriais existentes e, assim, refletir sobre como os diferentes paratextos (Genette, 2009) exercem uma grande influência na leitura e interpretação da obra.

Abstract: The book in Spanish language Diarios de Motocicleta (2004) by Ernesto Rafael Guevara de la Serna, Che Guevara, is one of the editions of his travel diary written between 1951 and 1952. This text was later revised and narrativized by him and was in the possession of his relatives for approximately 40 years until the authorization of its first publication, entitled Notas de Viaje (1993). In this research, the chronology of the editions is presented until the last one to compare the different editions and to reflect how the different paratexts (Genette, 2009) exert a great influence on the reading and interpretation of the book. 


\section{INTRODUÇÃO}

Ao longo de sua vida, Ernesto Rafael Guevara de la Serna demonstrou ser um leitor assíduo, como pode ser visto em diversos registros seus. Ele, mundialmente conhecido como Che Guevara, explicitou publicamente o conhecimento adquirido por meio de leituras nas áreas de filosofia, política, literatura. Esse gosto pelos livros acabou por incentivá-lo a transpor a condição de leitor e a aventurar-se como autor de suas próprias narrativas. Logo, pode-se afirmar que "assim como lê, Guevara também escreve. Ou, melhor, porque lê, escreve" (Piglia, 2006, 106).

$\mathrm{Na}$ condição de leitor, seu repertório foi variado. Como autor, era mais adepto da narrativa do $e u$, da escrita de si. Esse tipo de narrativa da memória registra e expóe seu ponto de vista sobre diversos acontecimentos. "Ele escreve sobre si mesmo e sobre o que lê, ou seja, escreve um diário. Um tipo de escrita muito definida, a escrita privada, o registro pessoal da experiência” (Piglia, 2006, 106).

Um de seus diários refere-se à viagem que ele e seu amigo Alberto Granado empreenderam entre 1951 e 1952. Nessa jornada, eles percorreram a América do Sul por, aproximadamente, nove meses, deixando o conforto de suas casas na Argentina para viajar de moto e, posteriormente, a pé e de carona. Assim, eles vivenciaram situaçôes precárias e conheceram lugares com paisagens fascinantes, em contraste com a difícil realidade da grande maioria dos habitantes sul-americanos.

Durante esse trajeto, Ernesto fez anotaçóes sobre o que viu e viveu. $\mathrm{Ou}$ como ele assegura, "sua boca narra o que foi contado aos seus 
olhos" (Guevara, 2004, 51, tradução nossa). Essas notas foram revistas e narrativizadas por ele após o término da viagem, ato confirmado pelo seguinte trecho:

Ao fazer estas notas de viagem, no calor do meu entusiasmo e escritas com o frescor do que senti, escrevi algumas extravagâncias e, no geral, creio ter estado bastante longe do que um espírito científico poderia aprovar. De todas as maneiras, [...] agora, há mais de um ano daquelas notas [...] prefiro fazer uma síntese do que escrevi antes (Guevara, 2004, 127, tradução nossa).

Esses apontamentos, mesmo revisados, não foram publicados $\mathrm{e}$ permaneceram guardados por aproximadamente 40 anos, quando só então seus familiares e o Centro de Estudos Che Guevara autorizaram a publicação. A editoração, que teve início em 1992 - ano de fundação do Centro de Estudos Che Guevara - só foi finalizada no ano seguinte. Nascia, então, o diário impresso sob o título Notas de viaje (1993), que foi uma publicaçáo módica feita sob a responsabilidade da editora Ocean Press - selo especializado em textos de revolucionários latino-americanos.

Essa obra constitui uma parte do arquivo pessoal de Che e sua edição esteve a cargo de sua viúva, Aleida March de la Torre, presidente do Centro de Estudos Che Guevara. Esse Centro, localizado em Havana Cuba, é responsável por manter os arquivos pessoais de Che e autorizar as publicaçóes em que seu nome consta como autor. Trata-se de uma 
instituição para estudar e promover seu pensamento, vida e obra. Nada é publicado sob sua autoria sem que haja a autorização dessa organização.

Após essa primeira publicação, o Grupo Editorial Planeta adquiriu os direitos de edição dessa obra em língua espanhola. Logo, por se tratar de uma grande editora, ela difundiu mais extensivamente esse diário sob o título Mi primer gran viaje (1994) e sua edição de bolso de 1997, sob o mesmo nome. Houve, também, a distribuição para que outras editoras efetuassem traduções em várias línguas como italiano - Latinoamericana - Duediari per um viaggio in motocicleta (1993), inglês - The motorcycle diaries (1995) e português - De moto pela América do Sul (1995) e Primeiras viagens (1996).

Baseada nesses diários publicados anos antes despontou a produção fílmica Diários de motocicleta (2004), do diretor brasileiro Walter Salles. Trata-se de uma adaptação cinematográfica que foi enorme sucesso de público e de crítica, tornando as histórias contadas por Che em seu diário conhecidas mundialmente por meio das telas do cinema.

Concomitantemente ao lançamento do filme, surgiu uma nova edição do livro em língua espanhola: Diarios de motocicleta (2004). Esse material, sem tradução para a língua portuguesa, contém inúmeras modificações editoriais em relação às primeiras ediçóes do diário no mesmo idioma, como: capa, fotos, prefácio, posfácio, comentários, introdução e anexos. A modificação desses recursos se configura em uma estratégia para captar novos leitores, já que "a transformação das formas através das quais um 
texto é proposto autoriza recepçóes inéditas, portanto, cria novos públicos e novos usos" (Chartier, 2002, 76).

Ao lançar essa edição ampliada, com título igual ao do filme, no mesmo ano de sua divulgação, o propósito pode ter sido variado, mas, tendo em vista que tanto editoras quanto produtoras fílmicas visam ao lucro, podese deduzir que um dos propósitos seja esse, já que "o filme se torna uma espécie de marca ou franchise, desenhada para gerar não apenas sequências, mas também produtos de consumo subordinados" (Stam, 2006, 30).

Em uma lógica mais utópica e menos lucrativa (afinal Che era contra a ideologia capitalista), pode-se pensar que essa reedição seja para propagar o conhecimento do estilo narrativo de seu autor, perceptível em suas páginas impressas. Ou ainda, que espectadores curiosos por saber mais detalhes da viagem do que aqueles vistos no cinema pudessem ter acesso à narrativa em uma versão mais ampliada. De qualquer forma, a reedição do diário, sob qualquer um dos possíveis propósitos, apresenta alguém pouco conhecido: um jovem Ernesto antes de ter se tornado o revolucionário Che Guevara.

Diante de tantas ediçôes, traduções e até de uma adaptação cinematográfica, um ponto de convergência pode ser notado: em todas elas percebe-se a exaltação de sentimentos como a esperança, a compaixão, a empatia. O Ernesto que se apresenta está conhecendo seus vizinhos sulamericanos e descobrindo a si mesmo como cidadão latino. Ele evolui e amadurece ao longo do percurso. É sua jornada de autodescoberta. É a formação dos ideais que o acompanharão dali em diante. 
Essa narrativa, disponível em ediçóes e suportes variados, traz à tona o nome de Che e de sua trajetória, já que "contar a história de uma vida é dar vida a essa história" (Arfuch, 2010, 42). É uma maneira de atualizar quem ele foi e de (re)apresentá-lo ao público do/no século XXI, da forma que o veem ou como querem que ele seja visto.

Mediante o exposto, a obra literária em língua espanhola Diarios de motocicleta (2004) é o objeto de reflexão deste texto que propóe a análise de alguns elementos editoriais da obra, não como forma de conseguir respostas objetivas sobre a organização e modificação em suas diferentes edições, mas sim, para que haja a observação sobre o quão importante são esses recursos e como eles demonstram cuidado em sua seleção a fim de que atinjam com êxito a mensagem a ser transmitida por eles: a de um jovem Ernesto sensível e empático.

\section{Paratextualidades}

Para verificar certas diferenças entre Diarios de motocicleta (2004) e algumas das ediçóes anteriores, é necessário que se estabeleça a nomenclatura a ser utilizada para referir-se a esses elementos: os paratextos. Esse termo, cunhado por Gérard Genette, em 1987, é utilizado para se reportar àquilo "por meio de que um texto se torna livro e se propóe como tal a seus leitores, e de maneira mais geral ao público" (Genette, 2009, 9). Mais explicitamente, os paratextos são compostos por "título, subtítulo, intertítulos, prefácios, posfácios, advertências, prólogos, etc.; notas marginais, de rodapé, de fim de texto; epígrafes; ilustraçóes; errata, 
orelha, capa, e tantos outros tipos de sinais acessórios, [...] que fornecem ao texto um aparato variável" (Genette, 2009, 9-10).

Por meio dessa explanação, extrai-se que em um livro há o texto conteúdo principal e escrito pelo autor em período anterior à publicação - e há os itens que fazem com que esse texto se torne um livro e esteja apto a ser vendido. Isso é, para que se tenha um material publicável, os paratextos devem estar presentes, visto que, ainda que seja realizada uma produção mais artesanal, um livro contém ao menos um título, uma capa. Pode-se afirmar, também, que eles são variáveis e pensados de acordo com o público-alvo e com os objetivos a serem alcançados pela obra, já que diferentes paratextos geram sensaçóes diversas em distintos tipos de leitores. Isso posto, olhar detidamente para o paratexto de uma obra é voltar a atenção ao que a maioria vê, mas náo apreende, observa e náo percebe. Sáo os detalhes que completam e protegem o livro, impondo um modo de usar e uma interpretação adequada ao propósito do autor (Genette, 2009). $\mathrm{Ou}$ ao de quem possui os direitos autorais, que, no caso de Diarios de motocicleta (2004) e de todas as ediçóes disponíveis, é o Centro de Estudos Che Guevara.

Em se tratando de determinar essa maneira de usar, ou seja, de ler uma narrativa, os paratextos fornecem algumas orientaçóes de leitura que podem inclusive alterar a percepção do leitor em relação ao texto propriamente dito. Algumas delas podem ser autorais - como o título dos capítulos ou da própria obra - e outras são editoriais. Estas estão a cargo da editora e obedecem a critérios estéticos, mercadológicos e/ou financeiros. Entre elas 
estão a capa (incluída a foto utilizada), a introduçáo, o prefácio, os anexos, entre outros.

Em Diarios de motocicleta (2004), a maioria dos paratextos é editorial, já que a obra é uma publicação póstuma e a seleção de quase todos esses recursos não esteve a cargo do autor, e sim, da editoração. Os elementos editoriais paratextuais presentes nessa obra são: título, subtítulo, capa, lombada, orelha, contracapa, comentários, sumário, introdução, prólogo, prefácio, itinerário, mapa do itinerário, ilustraçôes, fotos e apêndices (contendo um relato mais detalhado sobre o Peru e uma carta de Che a sua mãe).

Já em relação aos títulos dos capítulos, eles parecem ter sido elaborados pelo próprio Che, podendo, assim, constituir alguns paratextos autorais, que não serão explorados para ceder espaço aos editoriais, pois estes são mais explícitos em seu objetivo: evidenciar uma pessoa quase sem defeitos. Para ilustrar a relevância da escolha e da utilização de alguns desses recursos paratextuais editoriais, pode-se comparar a edição do diário de bolso, Mi primer gran viaje (1997) com a de Diarios de motocicleta (2004). Ambas as obras estão em língua espanhola, são da mesma editora, aludem ao mesmo texto escrito por Che e, apenas observando-as superficialmente, percebe-se que são muitas as diferenças entre elas: título, foto da capa, cores, tipo de fonte e tamanho da letra, textura do papel e tamanho do livro.

As alteraçóes dos recursos auxiliares a serviço do texto principal fazem com que, a não ser pelo relato do diário propriamente dito, tenha-se duas obras divergentes publicadas. Uma explicação para essas inúmeras 
substituiçóes está relacionada à indústria cultural e à sociedade de consumo, visto que, "as editoras publicam novas ediçôes de obras literárias adaptadas no mesmo período do lançamento da versão cinematográfica, e invariavelmente colocam fotos dos atores ou de cenas do filme na capa" (Hutcheon, 2013,57).

Assim, devido ao lançamento do filme, a obra que antes se chamava Notas de viaje (1993) e Mi primer gran viaje (1997) passa a ser Diarios de motocicleta (2004), nome adotado somente pela edição em língua inglesa de 1995 e que foi empregado pela narrativa fílmica. Pode-se notar, entáo, uma nítida estratégia de relacionar o filme ao livro e vice-versa, já que as obras fílmica e literária lançadas em 2004 possuem o mesmo título.

Essa alteração, bem como outras, ocorre porque os aspectos paratextuais são responsáveis por despertar o interesse do público por uma obra, adequando-a ao tempo, lugar e situação de comercialização. A imagem que se quer passar de um autor ou de uma obra também pode estar relacionada a essas mudanças. Logo, a atençáo editorial com o paratexto pode ser notada em todas as obras literárias e, também, em Diarios de Motocicleta (2004).

Os elementos paratextuais selecionados para mostrar a interferência que eles podem proporcionar na leitura da narrativa são o prólogo e o prefácio. Eles constituem termos sinônimos para designar o "texto que precede ou introduz uma obra" (Moisés, 2004, 371) e que serve para apresentá-la ao leitor. Ambos estão dispostos em sequência e são escritos por familiares de Che: sua filha e sua viúva, respectivamente. 
Iniciando pelo prólogo, para seguir a ordem de apresentação na obra, o primeiro a se destacar é que nas ediçóes anteriores do diário não havia esse item. Ele é elaborado pela filha de Che, Aleida Guevara March, e é incluído pela primeira vez nessa edição de 2004. Esse texto se caracteriza por ser uma apresentação de Che e de seu diário, em que é inegável a tentativa de passar uma imagem positiva dele, algo já esperado de uma filha que escreve um prólogo na obra de seu falecido pai.

Ao averiguar os treze parágrafos que compóem esse texto, que é apenas um dos anteriores à narrativa principal, percebe-se palavras e expressóes de carinho, admiração e respeito. Um dos trechos em que mais se notam a presença desses adjetivos está logo no início, na primeira página, quando ela menciona que seu pai

é capaz de descrever táo graficamente as coisas que faz, e eu náo as contaria nunca, mas que ao fazê-lo, demonstra uma vez mais até que ponto um homem pode ser honesto e pouco convencional. Se tiver de ser sincera, devo dizer que ao ler fui me apaixonando pelo homem que meu pai foi (Guevara March, 2004, 9, tradução nossa).

Em poucas linhas nota-se que ela atribui a seu pai qualidades vinculadas à honestidade e originalidade, por ele contar minuciosamente fatos de sua vida, que ela declara que náo contaria se estivesse em seu lugar. Também afirma que ao ler o relato foi se apaixonando pelo homem que ele foi. Diante disso, evidencia-se que é um texto muito subjetivo, repleto de vocábulos que remetem à admiração e ao amor de uma filha por seu pai. 
Outro fragmento também é relevante na demonstração da relação afetuosa que se pretende transmitir por esse texto. Verbetes relacionados à juventude, aventura e humanidade confirmam o papel do prólogo em indicar essas qualidades e virtudes de Che:

Este jovem aventureiro com ânsia de conhecimentos e uma grande capacidade para nos amar mostra como a realidade bem interpretada pode calar em um ser humano até o ponto de ir transformando sua maneira de pensar. Leiam estas notas, que foram escritas com tanto amor, soltura e sinceridade (Guevara March, 2004, 10-11, traduçáo nossa).

Consoante sua filha, o diário expõe a realidade das pessoas e dos lugares por onde seu pai passou e que, ao compreendê-la de maneira adequada, permite uma mudança em seu modo de pensar. Ele é retratado como alguém sensível e com anelo em aprender. Alguém sincero e com capacidade de amar seu próximo.

Essa imagem de Che, elaborada por meio do prólogo, também será reforçada pelo próximo paratexto: o prefácio escrito por sua viúva, Aleida March de la Torre. Nele, persiste o uso de palavras vinculadas à aventura, juventude, descobrimento, conhecimento. Também é explicitada a mudança interna de Che, ocorrida durante a viagem.

O leitor também pode comprovar a incrível mudança que se dá em seu interior, à medida que descobre a América Latina e chega ao seu coração desenvolvendo um sentido cada vez mais profundo de uma identidade 
latino-americana, convertendo-o em um precursor da nova história da América (March de la Torre, 2004, 13-14, tradução nossa).

As escolhas lexicais desse excerto realçam algumas particularidades, como a questão da identidade latino-americana, apresentando Che como um ser humano com interesse visceral pela América Latina e que, por isso, torna-se um pioneiro da nova história da América. Note-se, porém, que, diferentemente do prólogo, o prefácio utiliza menos palavras afetuosas, ainda que se façam presentes, deixando para o texto da filha o papel de apresentar o amor incondicional por Che.

Nesse prefácio, que está presente em todas as edições em língua espanhola do diário desde sua primeira publicação em 1993, a ênfase dada é na imagem de Che como alguém de extrema relevância para a história da América Latina, o que denota que esse pode ter sido um dos propósitos da publicação desde o início.

Outra característica expressiva desse texto é que, por meio dele, tem-se a primeira afirmação de que Che escreveu anotaçóes durante a viagem e somente depois de seu retorno à Argentina é que houve a revisão e narrativizaçáo desse relato, indicando uma preocupação do autor em tornar sua escrita apta à leitura.

Estas experiências foram escritas mais tarde pelo próprio Ernesto como um relato, oferecendo ao leitor um conhecimento mais profundo da vida do Che, especialmente em um momento que pouco se conhecia dele, e revelando detalhes de sua personalidade, de seu passado cultural e de suas habilidades narrativas (March de la Torre, 2004, 13, tradução nossa). 
Por esse parágrafo, pode-se verificar que o diário é tratado como um arquivo de uma parte mais desconhecida da vida de Che e que ele contempla aspectos tanto de sua vida pessoal quanto de seu estilo narrativo. Depreende-se também que esse texto não foi produzido a partir de memórias registradas somente durante a viagem e sem posterior leitura, já que há a afirmação de que ele retomou suas notas para transformá-las em narraçáo. Isso também é ratificado pelo próprio Che ao longo do diário.

Tal informação indica que a primeira manipulaçáo desse texto ocorre pelo próprio autor, pressupondo uma exclusão, seleção, correção, e, enfim, uma ponderaçáo por parte dele para definir a imagem a ser transmitida por seu relato em uma estratégia tanto de melhoria da escrita como de sua autorrepresentação.

Em relação à autorrepresentaçáo, trata-se do modo como um autor monta um retrato de si próprio. Sáo escolhas que modificam e interferem na maneira de se perceber a narrativa, pois, na maioria das vezes, o que importa náo é tanto o que se conta sobre si, mas como se conta. Para isso, podem ser utilizados os mais variados recursos, segundo o desígnio do autor ou da editoraçáa. Quando esses elementos são usados de acordo com uma técnica de autorrepresentaçấo bem elaborada e executada, eles podem inclusive se sobressair aos fatos. Como afirma Arfuch,

não é tanto o 'conteúdo' do relato por si mesmo - a coleção de acontecimentos, momentos, atitudes - mas precisamente as estratégias ficcionais - de autorrepresentaçâo o que importa. Não tanto a 'verdade' do ocorrido, mas sua construção narrativa, os modos de (se) nomear no relato, 
o vaivém da vivência ou da lembrança, o ponto do olhar, o que se deixa na sombra; em última instância, que história (qual delas) alguém conta de si mesmo ou de outro eu (Arfuch, 2010, 73, grifo do autor).

Assim, o autor pode tecer sua escrita com base no que acredita ser sua imagem ou de acordo com a imagem que idealiza de si próprio. Ele faz de suas palavras um espelho em que o que se projeta é o seu autorretrato, sua autorrepresentação, da maneira como ele a percebe ou como pretende ser visto. No caso de Diarios de motocicleta (2004), essas estratégias de autorrepresentação são escolhas lexicais e estilísticas adotadas pelo autor, ponto que não é o foco deste texto, mas que são ratificadas pelas alterações efetuadas em relação aos elementos paratextuais das diversas ediçóes da obra.

Portanto, os paratextos de Diarios de motocicleta (2004) podem ser entendidos como parte de um esquema organizacional feito segundo as técnicas de autorrepresentação de seu autor-narrador e/ou em prol dos objetivos do Centro de Estudos Che Guevara. Eles se caracterizam como recursos textuais capazes de alterar a percepção do leitor em relação às páginas que serão lidas e por serem responsáveis por despertar o interesse do público para essa leitura.

\section{UM MAPA (DE)CIFRADO}

Após verificar algumas características dos paratextos de Diarios de motocicleta (2004), mais especificamente do prólogo e do prefácio, não se pode deixar de mencionar a relevância de mais um paratexto: o mapa 
do itinerário. Isso porque, dentre os elementos paratextuais, ele é o que demonstra explicitamente uma lacuna nos fatos narrados e desperta a reflexão para uma contradição existente no diário publicado a que se tem acesso.

Para que se entenda como um mapa causa essa indagaçáo, há de se observar que, segundo os relatos do diário, Ernesto e Alberto passaram por Argentina, Chile, Peru, Colômbia e Venezuela, conforme itinerário da viagem presente em todas as ediçôes. Contudo, pelo mapa do itinerário se vê que a viagem não terminou na Venezuela. Esse mapa está presente em todas as ediçôes em língua espanhola, mas não há menção direta ao longo das demais páginas da ediçáo de 2004 sobre a ida de Che a Miami e seu posterior regresso à Argentina. $\mathrm{O}$ diário termina com ele em Caracas Venezuela, partindo e deixando Alberto por lá, pois este resolvera ficar. Ou seja, a não ser pelo mapa, não haveria como saber dessa ida a Miami.

Entretanto, comparando algumas ediçôes encontra-se a explicação do que consta no mapa. Em Mi primer gran viaje (1997) é possível encontrar um anexo em que seu pai, Ernesto Guevara Lynch, conta que Che ficou um mês em Miami. O que era para ser apenas uma escala rumo a Buenos Aires tornou-se uma parada de trinta dias por conta de problemas no motor do aviâo cargueiro no qual ele havia conseguido embarcar de carona em Caracas. Logo, a imagem do mapa do itinerário está correta e houve essa viagem.

Porém, seu pai também não fornece muitos detalhes. Apenas comenta que foram dias difíceis para o filho e relata uma de suas açóes quando 
finalmente regressou a Buenos Aires: "[Ele] se viu em apuros para poder suportar trinta dias com o exíguo capital de um dólar. Ficou em uma pensão, comprometendo-se a pagá-la quando chegasse a Buenos Aires, coisa que fez" (Lynch apud Guevara, 1997, 215, tradução nossa).

Os dias em Miami são limitados aos comentários que o pai de Che escreve nesse anexo do diário, resumindo trinta dias em três páginas (Lynch apud Guevara, 1997, 215-217). Um relato um tanto superficial de um pai que estava a milhares de quilômetros do filho e conta o que a ele foi dito ou o que ele julgou conveniente expor sobre seu filho. Também há a ênfase na honestidade de Che, ao afirmar que ele efetuou o pagamento de sua hospedagem em Miami quando retornou a Buenos Aires, conforme havia se comprometido.

Verificando outro trecho, seu pai afirma que Ernesto percorria a pé quinze quilômetros quase todos os dias para ir da pensão em que estava até a praia. Ele fazia isso, pois não tinha dinheiro para locomover-se de outra forma e queria conhecer o lugar onde estava. Seu pai ainda ressalta que, apesar das dificuldades, ele "passou muito bem, divertiu-se tudo o que pôde e conheceu os Estados Unidos, ainda que somente uma pequena parte" (Lynch apud Guevara, 1997, 216, tradução nossa).

Por esses excertos, percebe-se que são evidenciadas algumas qualidades de Che como a honestidade, a juventude e a positividade. Contudo, mesmo com o realce dessas características, em Diarios de motocicleta (2004) esse anexo simplesmente náo existe. Somente pelo mapa se identifica essa ida a Miami, após o embarque de avião na Venezuela. $\mathrm{O}$ fato de não 
haver a menção ao tempo que ele esteve por lá, pode levar o leitor sem conhecimento de outra edição do diário a crer que se tratou apenas de uma escala.

Logo, cotejando as duas ediçóes da mesma editora e do mesmo idioma - Diarios de motocicleta (2004) e Mi primer gran viaje (1997) - nota-se que são muitas as diferenças paratextuais entre elas. Mas, além dessas distinçôes editoriais perceptíveis entre as obras, outros pontos denotam questionamentos: se Che escreve durante toda a viagem, por que não há nenhum relato dos trinta dias em que ele esteve em Miami? Por que essa menção, escrita por seu pai, foi retirada da versão mais atual? $\mathrm{O}$ que o jovem Ernesto teria vivido aí que não possa ou não mereça ser divulgado? Essas questóes não conseguiráo ser respondidas objetivamente e com fundamentação comprovada. Esse tampouco é o objetivo. Entretanto, é instigante pensar em como é improvável que um viajante que registrou toda a sua viagem não tenha escrito nada durante os trinta dias finais dela, que náo estavam no roteiro e foram marcados pelo acaso.

Posto isso, não há como saber o grau de manipulação desses textos e se houve partes incluídas, excluídas ou modificadas. O que se pode afirmar é que foi realizado um planejamento e se teve um cuidado especial com esse material. Sua publicação foi pensada segundo alguns critérios.

Ao fazer essa análise comparativa das ediçôes de um mesmo diário que permaneceu sob a custódia de seus familiares por mais de quatro décadas, faz-se pertinente considerar que em toda sociedade e, por conseguinte, nesse texto de autoria de uma figura pública como Ernesto Che Guevara, 
a produção do discurso é ao mesmo tempo controlada, selecionada, organizada e redistribuída por um certo número de procedimentos que têm o papel de conjurar seus poderes e perigos, de controlar seu acontecimento aleatório, de esquivar sua pesada e temível materialidade (Foucault, 2007, 238).

Como Foucault afirma, a materializaçáo de um discurso carrega consigo poderes e perigos e, por isso, ocorre uma série de açôes na tentativa de prevê-las e controlá-las, já que ao divulgar um discurso como esse diário não há apenas elementos linguísticos reunidos em algumas páginas. $\mathrm{O}$ que está presente ali são signos portadores de valores e ideologias.

Essa divulgação, seguramente, foi uma grande responsabilidade para os familiares de Che que resgataram uma parte desconhecida de sua vida, sabendo dos ônus e dos bônus que isso poderia causar. Consoante ao que explica a citação, esse discurso, ao se tornar público, passou por alguns procedimentos na tentativa de controlar as reflexóes eternizadas pela materialidade do diário.

Todos esses procedimentos não são passíveis de mensuração, já que os manuscritos não foram divulgados. Mas, ainda que fossem, como saber se uma parte não teria sido omitida? Não há como saber. O que se percebe é que não foi um acontecimento aleatório e que a organização, a seleção e o planejamento estiveram presentes nessa produção.

Desse modo, sem ter as respostas para todas as dúvidas, mas possibilitando a reflexão sobre algumas hipóteses, faz-se necessário concentrar-se no que realmente consta no diário: a maneira como seus familiares o descrevem 
no prefácio, no prólogo, nos anexos e nos demais paratextos. Assim, por meio das páginas publicadas às quais se tem acesso, é possível estabelecer como linha interpretativa dessas escolhas paratextuais a construção de um Ernesto Che Guevara repleto de qualidades, no auge de sua juventude e da formação de seus ideais.

\section{Considerações finaIs}

Com os exemplos apresentados, retirados do prefácio, do prólogo, dos anexos e do mapa do itinerário, pode-se notar a relevância deles para o texto principal, ao entender que eles auxiliam a interpretação e o estudo do diário, fornecendo orientaçóes sobre o modo de ler e ressaltando pontos que, às vezes, podem parecer sutis e até imperceptíveis ao leitor mais distraído. Ademais, induzem a uma leitura mais suavizada da imagem de Che, por terem sido escritos por pessoas que o amam e o enaltecem. Algo um tanto previsível, pois alguém "para contar a vida de seu herói, realiza um processo de identificação e, consequentemente, de valoração" (Arfuch, 2010, 55).

Portanto, esse olhar atento aos elementos paratextuais é de grande importância em uma obra, porque remete a uma consideração sobre as razôes para se alterar um título, incluir uma foto e, inclusive, modificar totalmente os paratextos editoriais de uma versão em relação à outra, como foi o caso do livro aqui em questão. Ressalte-se, porém, que essa observação dificilmente traz respostas exatas e palpáveis, já que os responsáveis pela edição raramente revelam publicamente seus objetivos. 
E, por este estudo contemplar uma obra póstuma, o autor também não pode esclarecer ou confirmar qualquer uma de suas escolhas paratextuais. Logo, "a paratextualidade [...] é uma mina de perguntas sem respostas" (Genette, 2010,16).

Contudo, ainda que não haja uma resposta definitiva para as hipóteses levantadas na escolha de cada paratexto, a reflexão sempre se faz necessária, já que a reedição de uma obra de um personagem como Che, e, mais especificamente, dessa sua obra que permaneceu guardada por tanto tempo, indica que há um cuidado extremo com o que deve ser dito por ela e qual é a mensagem a ser transmitida aos seus possíveis destinatários.

Essa análise de alguns dos elementos paratextuais do diário antecipam ao leitor o que esperar da narrativa que se apresenta nas próximas páginas: um relato de viajantes aventureiros, cheios de compaixão e empatia, em busca de uma identidade latino-americana.

Pode-se depreender também que esses recursos paratextuais não foram pensados por seu autor, pois "autores não escrevem livros: não, eles escrevem textos que outros transformam em objetos impressos" (Chartier, $2002,71)$. Entretanto, mesmo que o autor não tenha escrito o livro em seu formato final, tanto os paratextos como a narrativa principal pressupóem uma manipulação e uma organização textual para que Che seja entendido como um indivíduo com atitudes generosas, distintas e heroicas.

Por fim, é essencial compreender que existem códigos verbais e visuais a serem decifrados ao longo da leitura dos materiais literários. Isso é o que ocorre com Diarios de motocicleta (2004). Faz-se oportuno, também, 
entender que não é possível obter as respostas para todas as indagaçóes, mas que esse texto busca esclarecer alguns pontos, questionar outros e suscitar novos tópicos de observaçáo.

\section{RefERÊNCIAS BIBLIOGRÁFICAS}

Arfuch, Leonor. $O$ espaço biográfico: dilemas da subjetividade contemporânea. Tradução de Paloma Vidal. Rio de Janeiro: EdUERJ, 2010.

Chartier, Roger. À beira da falésia: a história entre certezas e inquietude. Porto Alegre: Editora UFRGS, 2002.

Diários de motocicleta. Direção: Walter Salles. Produção: Edgard Tenenbaum, Michael Nozik e Karen Tenkoff. Intérpretes: Gael García Bernal, Rodrigo de la Serna, Mercedes Morán, Jean Pierre Noher, Facundo Espinosa, Mía Maestro. Roteiro: José Rivera. Estados Unidos e Argentina: Film Four e BD Cine, 2004. DVD (126 min.), son., color.

Foucault, Michel. A ordem do discurso. Traduçáo de Laura Fraga de Almeida Sampaio. 15. ed. São Paulo: Ediçôes Loyola, 2007.

Genette, Gérard. Paratextos editoriais. Tradução de Álvaro Faleiros. São Paulo: Ateliê Editorial, 2009.

Genette, Gérard. Palimpsestos. A literatura de segunda mão. Belo Horizonte: Ediçóes Viva Voz, 2010.

Guevara, Ernesto. Notas de viaje. Havana, Cuba: Ocean Press, 1993.

Guevara, Ernesto. Mi primer gran viaje. De la Argentina a Venezuela en motocicleta. Buenos Aires: Planeta Bolsillo, 1997.

Guevara, Ernesto. Diarios de motocicleta: notas de un viaje por América Latina. Buenos Aires: Planeta, 2004.

Guevara March, Aleida. "Prólogo". In: Guevara, Ernesto. Diarios de motocicleta: notas de un viaje por América Latina. Buenos Aires: Planeta, 2004, 9-11. 
Hutcheon, Linda. Uma teoria da adaptação. Tradução de André Cechinel. 2. ed. Florianópolis: Editora UFSC, 2013.

March de la Torre, Aleida. "Prefácio". In: Guevara, Ernesto. Diarios de motocicleta: notas de un viaje por América Latina. Buenos Aires: Planeta, 2004, 13-14.

Moisés, Massaud. Dicionário de termos literários. Sáo Paulo: Cultrix, 2004.

Piglia, Ricardo. "Ernesto Guevara, rastros de leitura”. In: Piglia, Ricardo.O último leitor. Tradução de Heloísa Jahn. São Paulo: Companhia da Letras, 2006, 98131.

Stam, Robert. "Teoria e prática da adaptação: da fidelidade à intertextualidade". In: Revista Ilha do Desterro, 51, 2006, 19-53. 